\title{
Dynamics Characteristics of Blast Furnace Shell
}

\author{
Dechen Zhang, Yanping Sun
}

College of Mechanical Engineering and Automation, University of Science and Technology Liaoning, Anshan, Liaoning , China, 114051

Zhangsun6411@163.com

Keywords: finite element analysis, analytical method, blast furnace shell, natural frequency

Abstract. Finite element method and structural mechanics method are used to study the blast furnace shell modal analysis and the natural frequencies and mode shapes have been calculated. The two methods were compared and validated, and the results provide a theoretical foundation for the anti-vibration capabilities design of blast furnace shell in the future .

\section{Introduction}

Blast furnace iron is the important equipment in steel enterprises. Actually it is a multi-disciplinary comprehensive equipment. Early from 1980s, blast furnaces are growing up everywhere in China, as it does today. Blast furnace shell is the main structure of a blast fumace. The anti-vibration performance of the furnace shell has great influence on the blast furnace. Natural frequency and modal identification of a $2830 \mathrm{~m}^{3}$ blast furnace was analyzed in Kawasaki Steel Corporation of Japan .The experts of Metallurgy Ministry studied the dynamic analysis of blast furnace in An steel Co. Ltd., Wu steel Co. Ltd and Bao steel Co. Ltd, Tang steel Co. Ltd, Ma steel Co. Ltd. The natural frequencies and natural mode of vibration of 16 blast furnaces were analyzed $[1,2]$.

In China, the stress calculation of blast furnace shells was developed early [3]. However, vibration analysis for blast furnace shell hasn't been studied. The vibration analysis and a finite element method of blast furnace shell were introduced in this paper. Then, the vibration problems of the An steel Co. Ltd New No. 4 blast furnace shell was analyzed and calculated. The natural frequency and vibration model of the blast furnace would be helpful for future anti-vibration design[4].

\section{Finite element analysis of blast furnace shell vibration}

Modal analysis was used to design the anti-vibration characteristics of a structure or machine parts. The main vibration characters are natural frequency and vibration mode, which are the important design parameters in designing the dynamic loading of structure [5,6].

The modal analysis includes modeling, loading, solving, modal expansion, and observing the results. Modal analysis determines the dynamic characteristics of blast furnace shell, includes the natural frequency, vibration mode and steady response. The finite element methods were used to analyze vibration mode of the furnace shell with irregular geometry.

Modal analysis method based on the premise that main vibration mode coordinates takes place of physical coordinates in a system without damping. The vibration differential equations were decoupled and independent differential equations were obtained. System natural frequency and vibration mode were calculated by solving the characteristic equation.

$$
\operatorname{det}\left|[\mathbf{K}]-\omega^{2}[\mathbf{M}]\right|=0
$$

where, $\mathbf{K}$ is the stiffness matrix; $\omega$ is the natural frequency, $\mathrm{rad} / \mathrm{s} ; \mathbf{M}$ is the mass matrix.

ANSYS was used in the modal analysis of No. 4 furnace shell in An steel Co. Ltd New. Mesh map was shown in Fig. 1. The constraint is the bottom of the furnace shell which is fixed.

The eighth order natural frequencies of blast furnace shell were analyzed by FEM. The results were shown in Table 1. The 1st order natural frequency is called fundamental frequency, as the table show, the base frequency was $3.6712 \mathrm{~Hz}$. 
Table 1 The eighth order natural frequencies of blast furnace shell

\begin{tabular}{ccccccccc}
\hline $\begin{array}{c}\text { Order } \\
\text { mode }\end{array}$ & 1 & 2 & 3 & 4 & 5 & 6 & 7 & 8 \\
\hline $\begin{array}{c}\text { Natural } \\
\text { frequency } \\
(H z)\end{array}$ & 3.6712 & 4.0588 & 6.4143 & 9.5734 & 11.630 & 12.095 & 12.797 & 13.669 \\
\hline
\end{tabular}

The main view of blast furnace shell was shown in Fig. 2.

Fig. 3 shows the commanding view of blast furnace vibration mode;

Fig.4 was the three-dimensional map blast shapes. Fig.4 shows that the first order vibration mode wave number of the blast furnace shell was 3 .

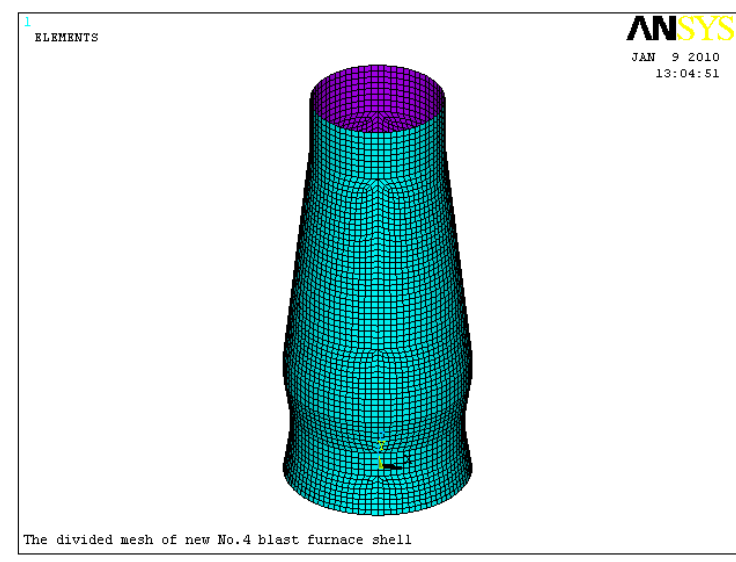

Fig. 1 Mesh of furnace shell

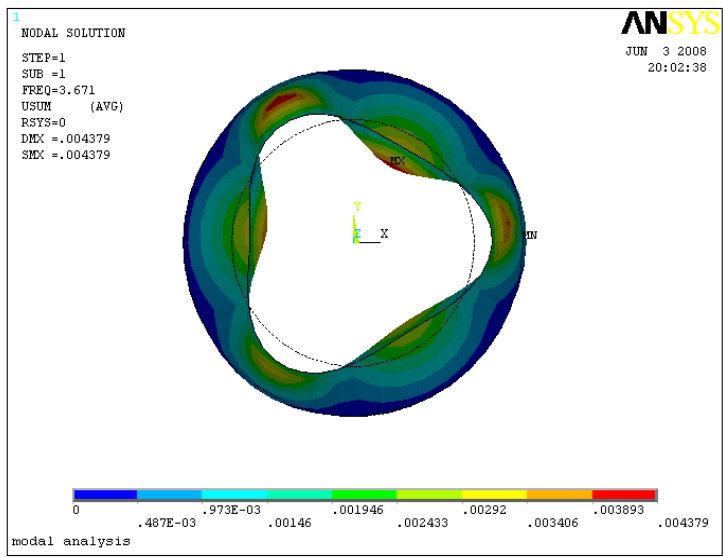

Fig. 3 Commanding view of blast vibration mode

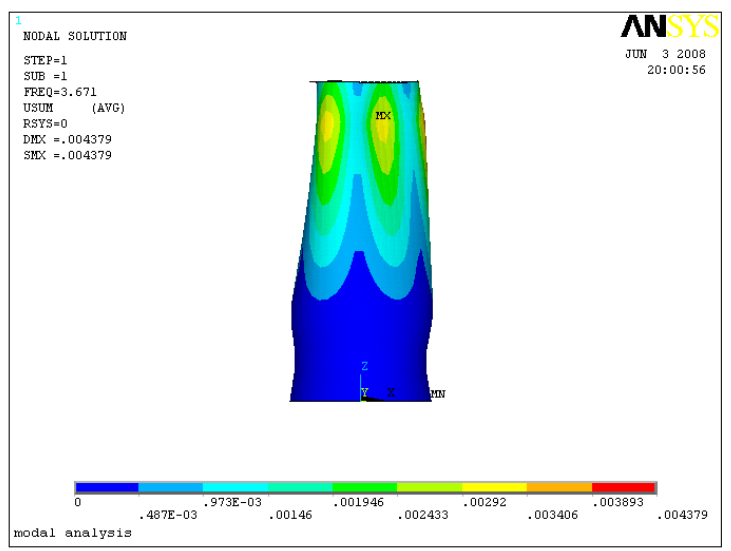

Fig. 2 Main view of blast vibration mode

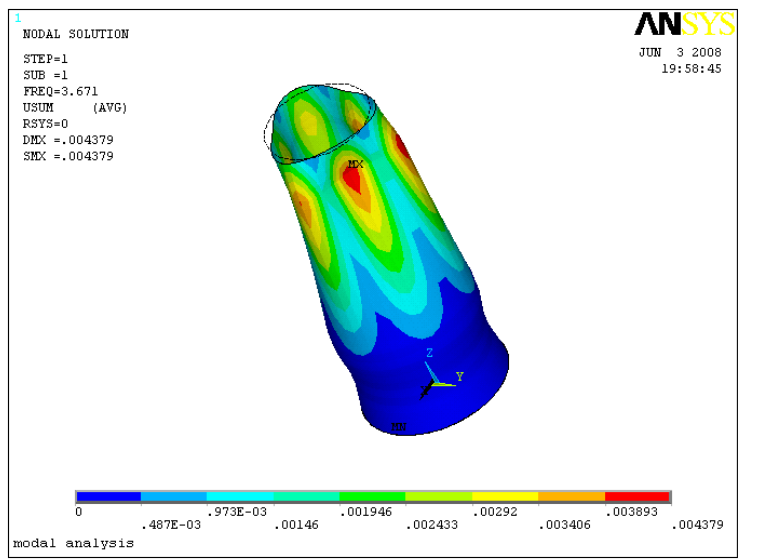

Fig. 4 Three-dimensional map of blast vibration mode

\section{Analytical calculation on blast furnace shell natural frequency}

Main parameters of new No. 4 blast furnace in An steel Co. Ltd. was shown as follows: Furnace shell height $L=31.875 \mathrm{~m}$, internal diameter of the furnace shell $D_{1}=12.1 \mathrm{~m}$, external diameter of the furnace shell $D_{2}=12.21 \mathrm{~m}$, elastic modulus $E=206000 \mathrm{MPa}$, density $\rho=7800 \mathrm{~kg} / \mathrm{m}^{3}$.

Analytical method is used to calculate the natural frequency of blast furnace. The natural frequency of cylindrical shell equation is [7]:

$$
\omega_{m n}^{2}=\frac{g}{\gamma h_{n p} R^{4}}\left[E h R^{2} \frac{\left(k_{n} \xi\right)^{4}}{T_{m n}}+D T_{m n}\right]
$$


where, $\omega_{m n}$ is the natural frequency, $\mathrm{rad} / \mathrm{s} ; \gamma$ is the density, $\mathrm{kg} / \mathrm{m}^{3} ; h_{n p}$ is the thickness conversion, ${ }^{m} ; R$ is the shell radius, $m ; h$ is the shell thickness, $m ; k_{n}, T_{m n}$ is the coefficient; $\xi$ is the $R / L$ value; $D$ is the rigidity related coefficient, $m^{4}$.

Based on beam theory, the natural frequencies were calculated. The bottom of the furnace shell is fixed, and the cantilever beam method was analyzed.

$$
\begin{aligned}
& \alpha=3.515 \\
& \omega=\frac{\alpha}{L^{2}} \sqrt{\frac{E}{\rho}} \sqrt{\frac{I}{A}} \\
& \sqrt{\frac{I}{A}}=\frac{1}{4} \sqrt{D_{1}^{2}+D_{2}^{2}}
\end{aligned}
$$

Where, $I$ is the moment of inertia, $m^{4} ; A$ is the area, $m^{2}$.

According to the beam theory, the blast furnace parameter were taken into equation (3) and (4), then:

$\omega=12.166 \mathrm{~Hz}$, the result was too large.

Analysis of cylindrical shell using equation (2), the natural frequency was obtained. $\omega=3.65 \mathrm{~Hz}$.

Beam and cylindrical shells model were used to calculate natural frequency of the furnace shell. The results are compared with the finite element analysis results. If beam method was used, the results are 3.3 times of the finite element analysis results. It was too large. But if cylindrical shells model was adopted, the results were almost consistent with the finite element analysis results. The results were almost reasonable. Therefore, the first order natural frequency could be calculated by cylindrical shell model, and the base frequency of blast furnace would be obtained.

\section{Conclusions}

Analytical method and the finite element method were used to analyze natural frequencies and vibration mode of An steel Co. Ltd new No. 4 blast furnace shell. The results show that the geometric parameters (height of the furnace shell, the radius of the furnace shell, the furnace shell thickness) have great influence on the natural frequency. Before the finite element complex calculations, taking cylindrical shell as a model, and using a simple formula to calculate the first order natural frequency of the blast furnace shell. Then, fundamental frequency of the blast furnace shell was analyzed. The analytical method and the finite element method were useful for mutual authentication. It plays a greater role in finite element method for complex structures. The calculation in this paper provides an important basis for the blast furnace anti-vibration capabilities design.

\section{References}

[1] Lilian Xiang, the basic design of BF Current Situation and Outlook, industrial building, Beijing, 199712

[2] Zhou Shanwen. BF seismic analysis, foundation and industrial buildings earthquake, Earthquake Press, Beijing, 1984 (268-289)

[3] Zhang Dechen.,finite element analysis of Angang Co. Ltd No. 11 blast furnace shell stress, iron, Wuhan, 1991, No. $5: 7-13$

[4] Bin Jiang,Lifan He and Jinsheng Ma. Noise and Vibration Control of Blast furnace gas regulator group area.Zhejiang Metallurgy.2004,1:34-35.

[5] Haijiang Cao.Vibration Analysis Technology on Trouble Diagnosis.Science \& Technology Information.2010,17:85.

[6] Chengbo Wu,Pengyan Xu and Ding Ma.Characteristics Analysis on Hot Blast Stove Vibration of BF.Metallurgical Equipment.2008,1:73-75.

[7] Antonov book Nicheng Sheng translation. Tower derrick design and calculation, Coal Industry Press, Beijing , 1979,35-49 